\title{
Syv Beowulf-anmeldere
}

\section{Af Andreas Haarder}

Har det angelsaksiske publikum sat pris på at høre Beowulf-digtet? Ja, formodentlig! Selvfølgelig var der nok nogle, der foretrak et andet digt om de samme, eller om andre, begivenheder. Men selve den kendsgerning, at det blev skabt, forudsætter en gruppe mennesker, der i det mindste var parat til at lytte til det og udtale sig om det på den ene eller den anden måde. Ingen af udtalelserne fra dengang findes bevaret, og undertiden gives der udtryk for undren herover. Det er dog mere mærkeligt, at der skulle gå over tusind år, før de første anmeldelser kom til at foreligge.

Beowulf fik sit andet publikum med året 18 5 . Hvor ufuldkomment det end blev udgivet, oversat (til latin) og kommenteret af den islandske lærde G. J. Thorkelin ${ }^{1}$ ), så forelå det $\operatorname{dog}$ omsider og kunne gøres til genstand for syv anmelderes opmærksomhed ${ }^{2}$ ).

I. De Danorum Rebus Gestis Secul. III \& IV. Poëma Danicum Dialecto Anglosaxonica. (Kbh. 1815).

2. Dansk Litteratur-Tidende (1815), nr. 26-28. Den anonyme anmelder, som kan have været tidsskriftets udgiver Peter Erasmus Müller (cf. Nyeste Skilderie af Kjøbenhavn (1815), sp. 1186 (\& 1046f.)), er her omtalt som Pem. - - Nyeste Skilderie af Kjøbenhavn (1815), nr. 6o, 63-66: $\gg$ Et Par Ord om det nys udkomne angelsaxiske Digt« og nr. 70-72: »Nok et Par Ord om Bjovulfs Drape«, ved N. F. S. Grundtvig. - - The Monthly Review LXXXI (1816), pp. 516-23, ved William Taylor of Norwich. (Anonym, men cf. Modern Language Notes LV (1940), p. 2 I o f.). - - Fenaische Allgemeine Literatur-Zeitung (1816), Ergänzungsblätter, nr. 45-46. Signeret Pia. Anmelderen, der ikke er identificeret, omtales således her. - - Kieler Blätter III (1816), pp. 307-27: 》Das angelsächsische Gedicht Beowulf, als die schätsbarste Urkunde des höchsten Alterthums von unserm Vaterlande«, ved Nicolaus Outzen. - - Iduna VII (Stockh. 1817), pp. 133-59; signeret G-s, i. e. G. W. Gumælius (cf. Iduna XI, p. 102). - - Göttingische gelehrte Anzeigen (1818), I, 5, pp. 41-47. Anmelderen er anonym. Tidsskriftet forkortes $G g A$. - - Grundtvigs anmeldelse vil blive omtalt sidst. 


\section{Dansk Litteratur-Tidende}

Denne anmeldelse var den første, der gik i trykken, og Pem er uden tvivl hæmmet af, at han så nøje måtte følge Thorkelins tekst og oversættelse. Der er dog forskellige fornuftige momenter $i$ hans kommentarer ${ }^{3}$ ).

Imod Thorkelins tidlige datering og den dermed uundgåeligt sammenhængende teori om kristen interpolation anfører han, at hele digtet er præget af kristne hentydninger (p. $426 \mathrm{f}$.). Samme indvending finder vi fremsat af Pia (sp. 357 f.), Outzen (p. 32I), Gumælius (p. I 52 ) og anmelderen i $G g A$ (p. 43 f. $)^{4}$ ), og indirekte af Grundtvig, for hvem problemet ikke kommer til at opstå.

Tilsyneladende er Pem klar over, at det kan virke vildledende at kalde digtet et Skjoldunge-epos, som Thorkelin gør det. På den anden side mener han, det virkelig var digterens hensigt, at de første ord: »Hwæt wē Gār-Dena - - « skulle stå som overskrift (cf. p. 4o6) over hele digtet, et vidnesbyrd om »det danske Navns« betydning i hine tider (cf. p. 405, 445). Også hos Grundtvig måtte Beowulf give anledning til nogen forfædrestolthed. Hos slesvigeren Outzen, derimod, kommer patriotismen til at dominere en hel anmeldelse.

Pem hævder, at Beowulf må være en bearbejdelse af en oldnordisk original (p. 428); eller rettere, som han senere er inde på det, der må oprindeligt have været mindst to digte, for indholdet peger jo på, at i hvert fald to dele er føjet sammen (p. 440). Tanken om en tvedeling i Beowulf, som senere skulle blive et centralt problem for litteraturkritikken, optræder ikke her i nogen vurderende sammenhæng. I det hele taget forsøger Pem ikke på at vurdere. Nævnes bør dog hans sammenlignende betragtninger over Beowulf og Eddadigtningen:

Digtets hele form er som flere angelsaxiske Digtes aldeles oldnordisk $\left.{ }^{5}\right) .\left[-{ }_{-}\right]$ De digteriske Udtryk ere [- - næsten alle af Skaldeqvadene bekiendte. I Fortællingens Gang findes den største Lighed mellem dette Digt og flere af de eddiske Sange om Volsungerne: samme Simpelhed, samme Omstændelighed $\mathrm{i}$ at udmale Handlingens enkelte Dele og atter igjen pludselige

3. cf. F. Gooley, ELH, A Fournal of English Literary History VII (1940), pp. $5 \mathrm{I}-54$.

4. cf. også Taylor, p. $5 \mathrm{I} 8 \mathrm{f}$.

5. cf. Gumælius (p. I58), som iøvrigt muligvis kendte anmeldelsen i Dansk Litteratur-Tidende. 
Spring, lignende Gjentagelser i de ofte forekommende Taler. Dog ville vi ikke lægge for megen Vægt paa denne Lighed [i.e. i forb. med teorien om en oldn. original], da den er en naturlig Følge af det poetiske Sprogs Uddannelse paa et vist Kulturtrin, og alt dette, naar de pludselige Spring undtages, ogsaa findes i Homer. Men flere Steder i Digtet findes ydermere en paafaldende Lighed i Udmalingen af karakteristiske Bevæggrunde [- - ]. Den Vidtløftighed, som findes i mange af Talerne, maae vel tilligemed de fromme Betragtninger tilskrives Angelsaxerne. Ligesom vi og her savne den kraftfulde Digteraand, der udtaler sig i flere af de eddaiske Sange (p. $43^{8}$ f., 440).

Vi savner i Beowulf den kraftfulde digteraand. Hvad end Pem mere præcist kan have ment, er det interessant at konstatere, at Grundtvig ved en lignende sammenligning må pege på den »Høihed og Dybde i Følelse og Betydning «, som efter hans skøn fremtræder som Eddadigtenes særkende (cf. infra).

\section{II}

\section{The Monthly Review}

Taylor genfortæller handlingen i Beowulf og oversætter nogle passager til moderne engelsk, men giver absolut ikke indtryk af nogen evne til at forbedre på den Thorkelinske version. I det hele taget giver anmeldelsen overmåde $\left.\operatorname{lidt}^{6}\right)$.

Visse senere kritikere foregribes, når Taylor finder digtets anden del, i. e. efter Beowulfs hjemkomst, »of inferior merit and interest«; men efter hans mening er der også:

a third part [- ]; a sort of epilogue, which [iflg. Taylor] narrates the old age and disease of Beoreulf, and his determination to die a voluntary death (p. 52I).

Selv om det ikke lykkes Taylor at fatte særlig meget af, hvad det hele drejer sig om, er det dog bemærkelsesværdigt, at han anbefaler digtet ikke blot til oldforskeren, men også til digteren:

- both the poet and the antiquary [- - ; it is the most brilliant corruscation of the boreal dawn of literature; and it may no doubt be applied to the discovery of historical truth, as well as to the decoration of the skies of fiction (p. 523).

6. Se dog R. W. Chambers, Beowulf. An Introduction (3. ed. 1959), p. 292. Det virker noget overraskende, når Taylor, $\mathrm{i}$ stedet for at bevare anonymiteten eller dog ændre det skrevne, indlemmer anmeldelsen, $\mathrm{i}$ en form der i alt væsentligt er den samme, i det senere værk Historic Survey of German Poetry I (1830), §6. 


\section{III}

\section{fenaische Literatur-Zeitung}

På en række punkter tages Thorkelins udgave her under behørig kritisk behandling. Af størst interesse er imidlertid Pias overvejelser med hensyn til digtets art:

Thorkelin overvurderede Beowulf ved at kalde det et Skjoldungeepos. Selv om det var et episk digt, ville navnet ikke dække indholdet (cf. Pem); men om et episk digt er der i virkeligheden slet ikke tale:

Hier ist nicht eine einzige Handlung des Lebens Beowulfs, die sich der Dichter zum Gegenstande seines Gesanges gewählt hat; es ist das ganze Leben seines Helden - (sp. 356).

Hvis der ligger noget af et argument her, illustrerer Pia det dårligt; han fortsætter:

es beginnt von seiner frühesten Jugend, da Higelak [- - ] des siebenjährigen Beowulfs Erziehung übernimmt - (idem).

Men sådan bliver Beowulfs liv netop ikke fortalt. De linier der hentydes til - »ic wæs syfan-wintre« etc. (1.2428 ff.) - tages på denne måde ud af deres sammenhæng. De rummer Beowulfs afskedsord. Han forventer at dø i sin uundgåelige kamp med dragen, og hans tanker drejer sig naturligt om det liv, han har gennemlevet, og de ting, der skete. Hans levned, som det sammenstykkes af Pia, er noget ganske andet end den digteriske beskrivelse. At digtet ender med heltens død og begravelse kan naturligvis ikke benægtes. Pia konkluderer imidlertid:

Es ist also, wenn es mit einem Kunstnamen belegt werden soll, kein episches, sondern ein kyklisches Gedicht (idem).

Og eftersom det drejer sig om en helt, der bekæmper uhyrer, har han endnu et navn for det:

ein Hexenmährchen, das zur isländischen blauen Bibliothek gehört (idem).

Pia rejser således to spørgsmål: I ) udgør Beowulf en episk helhed? og 2) er uhyrekampe passende episke emner?, og han besvarer begge benægtende ${ }^{7}$ ).

7. cf. også $G g A$, p. 47: Epische Maschinerei fehlt dem Gedichte«. 
Mange senere kritikere skulle komme til at dele det synspunkt, at uhyrekampene gør digtet mindre betydeligt, mindre episk. Men hvorledes kunne Pia forestille sig, at man ved at bortskære uhyrerne og alt hvad dem tilhører kunne åbenbare noget bedre?:

[Beowulf burde oversættes til tysk med en fyldig kommentar]. In diesem Commentar müsste man I) genau das Mythische vom Historischen absondern. Die [- - ] Halbmythologie (denn eigentliche Götter hat er [i. e. digteren] nicht), seinen Grendel mit seiner Mutter, allen seinen so mannichfaltigen Gespenstern und der ganzen ihn begleitenden Zauberey, den Meerweibern, den Elfen, den Nixen, und wie die sauberen Geschöpfe der Rockenphilosophie noch weiter heissen mögen, alle diese müsste man aus einander setzen, und zeigen, wie und wo sie entstanden, wie der Glaube an sie sich ausgebreitet u.s. w. Wäre man damit fertig: so finge man 2) an, das Hexenmärchen auszubrennen, worauf gewiss sehr viel echtes Gold herauskommen würde (sp. 363 , min fremhævelse).

Sandheden er selvfølgelig, at Pia - mere eller mindre bevidst - har forladt litteraturkritikerens usikre stade for at placere sig, mere trygt, hos historikeren: »Das Historische müsste man [- - zu erläutern suchen« $($ idem $)$.

Pia kritiserer Thorkelins klassiske udtryk og hentydninger:

So wie Hr. Th. Vedera Leode durch gens aeolica übersetzt: so hascht er auch sonst ängstlich nach römischer und griechischer Literatur, und verfährt also ungefär so, wie jener Münzsammler, der von seinen Münzen den edlen Grünspan abbeizen wollte: er raubt ihnen Originalität! (sp. 364).

Han synes her aldeles at have glemt den hekseproces, han netop selv har anbefalet.

\section{IV}

\section{Kieler Blätter}

Outzen angriber Thorkelins tidlige datering af Beowulf, ikke blot under henvisning til de mange kristne træk, men også af følgende grund:

Es verräth ja nicht allein einen wahrhaft dichterischen, sondern auch einen wirklich gebildeten Geist. [- - Es ist demnach ganz und gar kein Anschein, ja nicht einmal Möglichkeit, dass ein in seiner Art so vollendetes Meisterstück schon in früheren Zeiten hätte zu Stande gebracht werden können ( $p$. 32 I). 
Han er den første læser, der foreslår, at digtet har skullet danne forbillede for en ung prins, være et fyrstespejl (p. 327).

At der er tale om »ein in seiner Art so vollendetes Meisterstück « forbliver imidlertid et postulat, og »in seiner Art « forbliver i det vage, fordi Outzen ihærdigt prøver at bevise noget andet - ikke digtets storhed, men dets (lokale) tilhørsforhold, ejendomsretten til det og med denne motivering for sit arbejde kommer han på en måde til at foregribe senere, for en eftertidsbetragtning ikke harmløse, forsøg på at annektere Beowulf som eksponent for »ægte« germanskhed $\left.^{8}\right)$.

\section{V}

\section{Iduna}

I denne anmeldelse fremhæves sammensmeltningen i Beowulf af historie og myte. Grendel, som i virkeligheden repræsenterer et folk, er gjort til et uhyre, fordi dette folk var fjenden (p. ${ }_{3} 6 \mathrm{f}$., ${ }_{5} 6 \mathrm{ff}$.). Hvor dragen kommer ind i billedet fremgår ikke.

Eftersom Gumælius, skønt ret kritisk indstillet (cf. p. 149, I59), ikke i tilstrækkelig grad er i stand til at forbedre det digt, som Thorkelin præsenterer, falder det ham naturligt at introducere teorien om en fuskende redaktør:

en Angelsachsisk Christen, som [-] efter sit tycke ordnat, omarbetat och sammankastat fragmenter af kanske mer än ett [cf. Pem] äldre nordiskt hedniskt Epos, hwari de här förekommande händelser blifvit besungna (p. 153).

Denne mand, der var uden større fortrolighed med de skildrede begivenheder (p. I5I f.), kan vi takke for digtets nuværende tilstand. Det var ikke så lidt der gik tabt: »hwarwid allt det speciella och lifligt utmärkande förswunnit«!

På baggrund af den stærke fornemmelse hos Gumælius af uorden, dunkelheder og gentagelser ( $p$. I $5_{\text {I f.) }}$, kunne man ikke forvente meget i retning af litterær vurdering:

Arbetet har åtskilliga sköna ställen. Det yppiga bildspråket blir dock, för en wid Eddasångerna owan, snart tröttsamt, och förswårar läsningen (p. $15^{8}$ ).

8. Det nationalistiske spøgelse fornemmes tidligt med værker som J. P. E. Greverus, Empfehlung des Studium der angelsächsischen Sprache für Schule und Haus (Oldenburg 1848 ) og Karl Simrock, Beowulf, Das älteste deutsche Epos uebersetzt und erläutert (Stuttgart und Augsburg 1859). 


\section{Göttingische gelehrte Anzeigen}

Den korte anmeldelse rummer en ganske god kommentar til dateringsspørgsmålet og diskuterer $\mathrm{i}$ forlængelse heraf det mytiske element i digtet (p. 43 ff.). (Som hos Gumælius peges der i øvrigt på, at Grendel er både historisk og mytisk). I Grendelfamilien mødes kristendommen med nordisk, og endog græsk, mytologi. Alt i alt finder anmelderen, at digtet har størst lighed med -

einem dunkeln Wolkengebilde, dessen Theile so in einander zerfliessen, dass nur hier und da ein bestimmter Umriss erscheint (p. 45).

Han stiller spørgsmålet om værdien - den (historiske og) litterære værdi - af en sådan »Wolkengebilde«, men bringer sig derved i en vanskelig situation. Han er kritikeren, der udtrykkeligt vedgår at mangle kendskab til såvel oldengelsk som oldislandsk (p. 42) og at have valgt at godtage, og nærme sig digtet via, Thorkelins latinske oversættelse (p. 42 f.). Han kan prise beskrivelsen af livet, som det genspejles i Beowulf - han finder her »ein schönes Streben nach Veredelung « (p. 47) - men han må uvægerligt fortsætte:

Diese Züge in den Sittengemählden, die das Gedicht enthält, würden das aesthetische Interesse des Ganzen mehr erhöhen, wenn nicht die Composition so dunkel, und der Styl so aphoristisch wäre, dass man nur mit Mühe den Faden findet und fest hält (idem).

Hans sammenfattende svar på værdispørgsmålet lyder vel nogenlunde, som man kunne vente det af en kritiker, der vil undgå at sige for meget:

Das Gedicht, so wie es im Originale mit der wörtlichen lateinischen Uebersetzung vor uns liegt, ist [-], als Gedicht betrachtet, von keinem hervorstehenden Werthe, aber auch nicht ohne wirklich poetische Stellen, und vorzüglich merkwürdig als Denkmal der Sprache und Denkart seiner Zeit, und als Beytrag zur ältern scandinavischen Völkergeschichte (p. $4^{2}$ ).

Et ret negativt svar, fra en litterær synsvinkel. Men anmelderen gør dog opmærksom på, at det er Thorkelins værk, der danner basis for hans bedømmelse, hvilket sætter læseren i stand til at skelne mellem Thorkelins Beowulf, d.v.s. først og fremmest den latinske oversættelse, og det oldengelske digt af samme navn. I højere grad end visse af medanmelderne røber han en bevidsthed om, hvilke græn- 
ser en ugunstig situation naturligt må sætte for, hvad der måtte være af evne til at øve kritisk virksomhed:

- ob das Ganze einen wahrhaft poetischen Ton hat, lässt sich nicht aus einer Uebersetzung abnehmen, wie diejenige ist, die wir hier vor uns haben (p. 47).

Han ville formodentlig have fundet nogen sympati hos Grundtvig, en langt bedre kritiker, men så harmfuld over pseudo-lærdhed.

\section{VII}

\section{Nyeste Skilderie}

Grundtvig er mindre urban end sine medkritikere. Selv om heller ikke han har nogen forhåndsfortrolighed med oldengelsk - oldislandsk kender han derimod - er han i stand til at fatte, hvor nemt det i mange tilfælde måtte være at rette og forbedre Thorkelins arbejde, og han finder det skandaløst, at Pem i et tidsskrift, der så absolut gjorde krav på at besidde lærdom og kritisk evne, i så høj grad ville acceptere et mangelfuldt værk og derved vildlede den ukyndige læser.

Hovedparten af hans anmeldelse beskæftiger sig med at fremdrage de mange fejl, som Thorkelin efter hans mening har begået, og som Pem har undladt at gøre opmærksom på. Han åbenbarer her sine evner, ikke blot som en forsker, der i en lang række tilfælde havde ret, men også som litteraturkritiker. I virkeligheden er de to funktioner indbyrdes afhængige: Han har en stærk fornemmelse af, at mange af hans ændringsforslag gør digtet bedre. Et oplagt tilfælde er genskabelsen af Skjolds (Scylds) sidste rejse. Det ville være forkert at påstå, at han på dette tidspunkt er oldengelsk forsker, men han er allerede blevet begejstret for digtet, og det er først og fremmest hans sympati som læser og litteraturkritiker, der gør ham til en bedre kvalificeret Beowulf-forsker end de andre. Hans overbevisning om, at det ikke blot er en interessant og problemfyldt oldsag han har med at gøre, udretter store ting for ham. Hans digteriske bevidsthed gennemsyrer anmeldelsen. Digtet frembyder mange interessante momenter for historikeren Grundtvig; men dets poetiske værdi er i lige så høj grad omtale værd; det var sømmeligt, siger han,

at enten Udgiveren eller en Anden forklarede på Modersmålet Kvadets Indhold, og viisde hvad vi alt flux kunne skjønne om dets poetiske og historiske Vard (sp. 945, min fremhævelse). 
Og hvis det somme tider er småt med de historiske oplysninger, er der jo stadigvæk digtet, og læserens mulighed for at læse og glæde sig over det:

Tiende, ellevte og tolvde Sang beskrive Bjovulfs Nattevagt og Kamp med Grændel, have meget poetisk Værd, men naturligvis intet egentlig historisk (sp. IOOI).

Mange passager forekommer Grundtvig dunkle; men selv om hans anmeldelse røber lige så mange svare bestræbelser for at få dem til at give mening, er han ikke tilbageholdende med sine lovord. I forbindelse med hans læsning af Skjold-episoden bliver det argument, som er en stimulus for hans arbejde hele vejen igennem, kompetenceargumentet - Beowulf er en kompetent digters værk - direkte fremført:

$\mathrm{Nu}$ vil Ingen nægte, at Dette ubeseet er langt rimeligere, at det er fast utroligt om en Skjald, der viser at han var ingen Fusker i sin Konst, at han vilde strax $\mathrm{i}$ Indledningen rykke os ind i en mørk Tale, som hverken er hugget eller stukket, men uden Sammenhæng ei alene med hans Hovedsag, men med Alt i Digtet - (sp. I 123$\left.)^{9}\right)$.

Men allermest slående illustrerer Grundtvigs første vurdering af digtet som helhed hans overbevisning om, at det er perfekt $\mathbf{i}$ sin art. Denne kunstneriske fuldkommenhed er det, der på godt og ondt lader Beowulf fremtræde som unikt i sammenligning med den nordiske Eddadigtning:

- dette Kvad, Bjovulfs Drape, som vel maae kaldes dets passeligste Navn, er saa ganske ene i sit Slags, at jeg ikke tør hensætte det i Fag med noget af de Kvad vi have fra Nordens Oldtid, thi Man sporer her i Anlæg og Udførelse en vitterlig Konst, om jeg saa maae sige, der forunderlig besvogrer sig med den gamle danske Trohjertighed og Simpelhed. De eddiske Kvad om Volsunger og Niflunger ere uimodsigelig dette Kvads næste bekjendte Frænder, men Sødskende vorde de aldrig for Beskuelsen, deres Høihed og Dybde i Følelse og Betydning savner Bjovulfs Drape, men derfor er den ei heller som de kjæmpelige Brudstykker der kun have Sammenhæng og Eenhed i det Usynlige, den er et favert, smagfuld ordnet og udpyntet Heelt, og vilde en Skjald i Konstens Barndom frembringe et Saadant, maatte han nøies med en verdslig Eenhed, lade Alt bevæge sig om sin Helt, Alt kaste Glands paa ham. Saa er det virkelig og Kvadet er i alle Maader Bjovulfs aandelige Bautasteen af smeltet Guld som skinner fra Hroneklint vidt over Havet og kundgjør

9. cf. sp. I0 I5: 》Bjovulfs Tale [- $]$ for Dragekampen $[--$ er] i den latinske Oversættelse saa forhutlet, at der er ikke Mening end sige Fortælling og Skjønhed at finde«. 
Styrmandens speidende Øie Sø Gothens Hæder, skjøndt det ei skal nægtes, til Skjaldens Priis, at den kjender sin Lavhed under den Himmel, mod hvilken den peger (sp. $1027 \mathrm{f}$.).

»En vitterlig Konst«, »et favert, smagfuld ordnet og udpyntet Heelt « - det er ord, som Grundtvig ikke skulle komme til at gentage. Som tiden gik, og han opnåede større fortrolighed med digtet, fandt han det ikke muligt at fastholde denne sammenfattende vurdering ${ }^{\mathbf{1 0}}$ ).

Som vi har set, hænger hans betydningsfulde indsats på dette tidspunkt sammen med, at han kan kombinere sin evne som forsker med en fantasifuld indlevelsesevne som litteraturkritiker. Ironisk nok bliver netop fantasien, der var så vigtig for hans forskning, et nøgleord og et skældsord i den række af fornærmede kommentarer, der fulgte hans anmeldelse. Thorkelin hentyder til hans »indbildningsrige Hjerne «, »skabende Indbildningskraft «, »drømmesvangre Hjerne« eller blot til hans »Phantasie« og hævder, at han »digter paa sin egen Haand $\left.\ll^{11}\right)$. Ved meddelelsen om, at Grundtvig vil foretage en dansk poetisk oversættelse af Beowulf, udtrykker Pem sin ængstelse for, at »Grillenfængerier《 vil præge værket ${ }^{12}$ ).

Grundtvig bliver angrebet for at kombinere uvidenhed med fantasi. Denne kritik er ikke retfærdig. Han udtrykker selv følgende ønske:

at [-] visse Folk dog engang vilde lade den underlige Grille fare, at jeg hader Grundighed, fordi jeg af mit inderste Hjerte hader det skinlarde Væsen og alle Skingrunde, samt at jeg skulde lade mig saa forskrækkelig tyrannisere af en utæmmet Phantasie, thi ihvorvel jeg ingenlunde kan tjene Udg. eller Nogen med enten at oversætte Bjovulfs Drape eller overalt gjøre Noget, uden Phantasie, mener jeg dog at min ivrige Omgang med Grammatik og Lexicon [ved Hickes og Somner] maae frikjende mig for den Beskyldning ei at kunne eller ville holde Styr paa min Smule Phantasie med et Gran Fornuft (sp. II44f.).

Taylor er som Beowulf-anmelder sympatisk indstillet, men temmelig inkompetent. Outzens bidrag er ikke nogen egentlig anmeldelse men et forsøg på at placere alt $\mathrm{i}$ hans eget fædreland. Pem, Gumælius og anmelderen i $G g A$ er for afhængige af Thorkelin, men

I o. cf. min afhandling i Grundtvig Studier 1965.

1 1. Nyeste Skilderie (1815), sp. 1059, 106o, 1079, 1080, 106o f.

12. Dansk Litteratur-Tidende (1815), p. 46r (cf. Thorkelin, Nyeste Skilderie (1815), sp. 1080). 
holder en vis standard. Det samme gør Pia, vel nok en mere skarpsindig kritiker, som i øvrigt forsøger at behandle genreproblemet. Grundtvigs anmeldelse er af en kvalitet, der placerer den i særklasse.

De berører allesammen problemer, der med skiftende vægt har præget Beowulf-forskningen indtil i dag. Grundtvig er den eneste, der kan gøre krav på også at blive kaldt litteraturkritiker.

Men de syv kunne være enige om, at noget betydningsfuldt var sket: Beowulf var blevet modtaget.

Eller modtaget påny - på en anden måde, i en anden verden. 